\title{
Biodiesel Production from Waste Margarine Using Homogeneous Catalyst Potassium Hydroxide
}

\author{
Pascal Mwenge, Neliswa Dlamini, Hilary Rutto and Tumisang Seodigeng
}

\begin{abstract}
Biodiesel, an eco-friendly fuel is challenged by the high production cost mainly due to the cost of feedstocks. Waste margarine appears to be one of the alternatives. This work aimed at producing waste margarine biodiesel using a homogeneous catalyst potassium hydroxide $(\mathrm{KOH})$. A laboratory scale reactor consisting of flat bottom flask mounted with a reflux condenser, a hot plate as heating element equipped with temperature, timer and stirring rate regulator. The effects of four reaction parameters were studied, these were: methanol to oil ratio (3:1 to $15: 1)$, catalyst ratio (0.3 to $1.5 \mathrm{wt}$. $\%$ ), temperature $\left(30\right.$ to $70{ }^{\circ} \mathrm{C}$ ), time (20 to 80 minutes). The highest yield of $91.13 \%$ was obtained at $60^{\circ} \mathrm{C}$ reaction temperature, 9:1 methanol to oil molar ratio, 0.9 wt. \% catalyst ratio and 60 minutes. The important biodiesel fuel properties were found to be within specifications of the American Standard Test Method specifications (ASTM). It was concluded that waste margarine can be used to produce biodiesel as a low-cost feedstock.
\end{abstract}

Keywords-Biodiesel, Homogeneous catalyst, Transesterification and Waste Margarine.

\section{INTRODUCTION}

BIOFUEL ingenuity has been backed by many governments policies in the pursuit of lowering dependency on fossil fuels and the quest for energy security through partially replacing the limited fossil fuels and decreasing the threat to the environment from exhaust emissions (greenhouse gases) and global warming [1]. Biodiesel is grander as compared to conventional diesel in terms of its lower Sulphur content, aromatic content and flash point. Biodiesel is basically Sulphur free and non-aromatic while conventional diesel can have up to 500ppm $\mathrm{SO}_{2}$ and 20-40 wt. \% aromatic compounds. These advantages could be a crucial solution in reducing urban pollution, since the transport sector is the major contributor to the total gas emissions in the atmosphere [2]

The oils and fats used for biodiesel production range from edible oils to animal fat. These oils and fats are also used in the food industry. This is a stumbling block for the biodiesel industry to overcome as it eats on the food sources. The use of edible oil for fuel is not a viable solution to the energy crisis, by using food to fuel motor vehicles is unethical, since there is starvation of majority of global population [3]. In the current day situation, biodiesel production cannot depend upon virgin vegetable oils; biodiesel ought to be produced in a way that does not cut into food supplies. An approach to resolve this problem is to use waste from vegetable oils, collected from

Pascal Mwenge, Neliswa Dlamini, Hilary Rutto, Tumisang Seodigeng Vaal University of Technology, South Africa restaurants and food processing industries so to produce biodiesel. These oils can successively be more cost-effective to use as feedstock for biodiesel production [4]. There are a lot of losses during the production of butter and margarine, which averages 5tons of waste oils being produced in these factories every month. These wastes are flushed from production lines and disposed of by municipal utilities, such as sewage systems and landfills [5].

Vegetable oils, unlike diesel fuel, comprise mainly of saturated hydrocarbons that are triglycerides. These triglycerides consist of esters and fatty acids. These fatty acids differ in the length of the carbon chain and the number of double bonds [6]. The biodiesel synthesis has two main reactions, which are transesterification and esterification. The main product for both reactions is Fatty Acid Alkyl Esters (FAAE), despite that the main reactants differ. The main reactant for the transesterification reaction is triglyceride, while the reactant for the esterification reaction is free fatty acid. Transesterification is where an ester is formed from one form to the next [7]. Transesterification is the main used method of biodiesel production, which is a three steps reaction in which the triglyceride reacts with alcohol to produce an ester and diglyceride, followed by the diglyceride reacting with alcohol to produce another ester and a monoglyceride. And lastly, alcohol reacts with monoglyceride to form the third ester and glycerol [8].

A catalyst can be described as a substance that changes the rate of a reaction without being part of the reaction itself. Catalysts are used to speed up the rate of reaction; the catalyst changes the mechanism of the reaction. This mechanism lowers the activation energy and in turn, increasing the rate. A catalyst does not affect or shift the equilibrium of the reaction [9]. There are two types of catalyst that can be used in the production of biodiesel; the catalysts can either be homogeneous, and heterogeneous (characterised as acid, alkaline and enzymatic). In earlier years of biodiesel production, more research was focused on the heterogeneous catalyst with the hope of decreasing the production cost as the catalyst could be reused. The disadvantage of using the heterogeneous catalyst is that the operating temperature has to be quite high for the catalyst to work efficiently[10], this then makes a homogeneous catalyst a viable option as the operational cost are far lower. Also, the reusability of the heterogeneous catalyst is not favourable, according to [11], who reported there was a drop in the yield from $96.8 \%$ to $83.1 \%$ after just three cycles. 
With increasing anxieties with regards to environmental impacts and the skyrocketing prices of petroleum has encouraged extensive studies to identify different fuel sources. Biofuels have attracted researchers' attention globally due to its renewability, biodegradability and low gas emission [12]. Waste margarine has been known as a possible feedstock in the production of biodiesel. The waste margarine can be obtained at a low cost, which will, in turn, decrease the production cost. The study aimed at producing biodiesel from waste margarine using potassium hydroxide as a catalyst. In this study, the effects of process parameters on the biodiesel yield, such as methanol to oil ratio, catalyst ratio, reaction time and temperature, were investigated. The fuel properties, such as flash point, density, viscosity, sulphur and water content, were evaluated.

\section{MATERIALS AND METHODS.}

\section{A. Materials and reagents}

The waste margarine was sourced from a local margarine manufacturing plant. Potassium hydroxide (85\%) used as a catalyst for the transesterification, Methanol (99.5\%), Phenolphthalein Indicator used as an indicator, were sourced from ACE (Associate Chemical Enterprises) a local laboratory chemicals supplier.

\section{B. Experimental Design}

The experimental design used in this paper was one factor at a time (OFAT). The parameters were methanol to oil ratio, catalyst ratio to the oil ratio, temperature and reaction time.

TABLE I

EXPERIMENTAL DESIGN

\begin{tabular}{lllccc}
\hline Parameter & \multicolumn{5}{c}{ Variable level } \\
\hline $\begin{array}{l}\text { Methanol to oil ratio } \\
\text { (mole/mole) }\end{array}$ & 3 & 6 & 9 & 12 & 15 \\
Catalyst ratio (wt. \%), & 0.2 & 0.6 & 0.9 & 1.2 & 1.5 \\
Temperature ( $\left.{ }^{\mathbf{0}} \mathrm{C}\right)$, & 30 & 40 & 50 & 60 & 70 \\
Time (minutes) & 20 & 35 & 50 & 60 & 80 \\
\hline
\end{tabular}

\section{Experiment Set- Up}

The basic setup involves a reaction vessel that comprises a two-neck round-bottom flask that was fitted with a condenser and temperature controller. The condenser was fitted to make sure that any evaporated methanol does not leave the system when during the reaction at temperatures near or higher than the boiling point of methanol. The temperature controller was used to control the reaction temperature by automatically regulating the set reaction temperature. The reaction vessel was placed on a heating plate to retain the heat of the reaction. In the reaction vessel was also a magnetic stirrer to agitate the reaction mixture.

\section{Experimental procedure}

The waste margarine was heated at $110^{\circ} \mathrm{C}$ for an hour; then 1 gram of the heated margarine was placed in a conical flask. $10 \mathrm{ml}$ of isopropanol and three drops phenolphthalein were added to the flask. The mixture was heated for 10 minutes while using a magnetic stirrer to mix all the contents. After being cooled, the mixture was titrated with $0.1 \mathrm{~N} \mathrm{KOH}$ standard. The procedure was done in triplicate to get the average percentage. The Acid Value (AV) was calculated using (1), and the FFA percentage was obtained using (2). The FFA was found to be $1,79 \%$ which is below $2 \%$ which means the transesterification process could use $\mathrm{KOH}$ as the catalyst will not form an undesirable side reaction of saponification, which could decrease the ester content.

$$
A V=\frac{m \text { of } K O H \times N \times 56}{\text { weight of sample }}=m g \text { of } \mathrm{KOH}
$$

$$
F F A \%=A V \times 0.503
$$

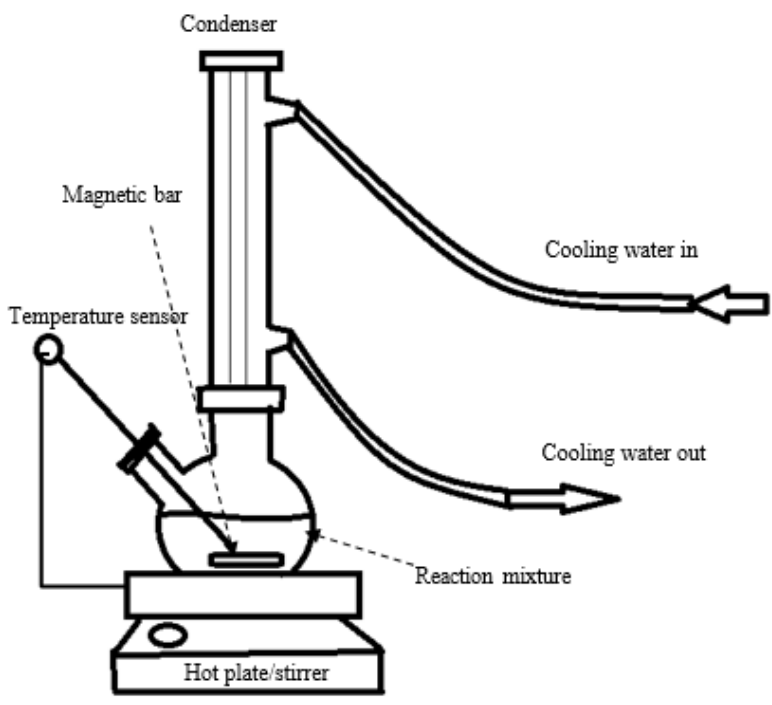

Fig.1 Experiment set-up

To ensure that little to no traces of water are present in the waste margarine, the oil was heated at a temperature of $105^{\circ} \mathrm{C}$ so to evaporate any water present, the reason of doing so is to prevent saponification reaction during the transesterification reaction, which is favoured by the presence of water. The condenser connected to the reactor vessel was cooled with tap water. Potassium methoxide was produced by mixing the required amount of methanol and potassium hydroxide. Oil was placed in the conical flask heated to the set temperature, once the set temperature was reached the methoxide was added to the reacting vessel and the timer was started. The methanol to oil molar ratio and catalyst ratio, reaction time and temperature were varied according to the experimental design. When the reaction time elapsed, the mixture was then emptied into a separating funnel where it separated into two layers the biodiesel and the glycerol layer. The glycerol layer the much denser fluid at the bottom was removed, leaving the biodiesel in the flask. The biodiesel was then washed with distilled water at $60^{\circ} \mathrm{C}$; this was done to ensure that any traces of methanol and $\mathrm{KOH}$ are washed off from the biodiesel. The washed biodiesel was then dried using a heating plate at $105^{\circ} \mathrm{C}$ until no trace of water was observed. The product was then cooled, and the biodiesel yield was calculated as per (3). 
Biodiesel yield $=\frac{\text { Mass of dry biodiesel }}{\text { Mass of ofl }} \times 100 \%$

\section{RESULTS AND DISCUSSION}

\section{A. Effect of process parameters}

The effect of methanol to oil molar ratio was evaluated at 0.9 wt. $\%, 60^{\circ} \mathrm{C}$ and 60 minutes, constant catalyst ratio, temperature and time, respectively. This is shown in fig. 2 . Methanol to oil molar ratio was varied from 3:1 to $15: 1$ at 3:1 increment. The Influence of methanol to oil ratio is one of the most significant dynamics affecting the conversion efficiency of waste margarine to biodiesel yield. There was a steady increase in the conversion of the methyl esters content, and the highest yield was obtained at 12:1 (mole/mole) yielding $89.55 \%$. The stoichiometric molar ratio of methanol to oil in the transesterification is 3:1 and the reaction is reversible, then higher molar ratios are required to increase the miscibility and to enhance the contact between the alcohol molecule and the triglyceride [13]. Reference [14], obtained their highest yield at a ratio of $6: 1$. For the 15:1 molar ratio, the separation of glycerol became complex, and therefore the actual yield of biodiesel was reduced as a result of a fraction of the glycerol remaining in the biodiesel stage. The molar ratio of 9:1 seems to be the most suitable as there was no must difference in the yield as compared to the ratio of 12:1.

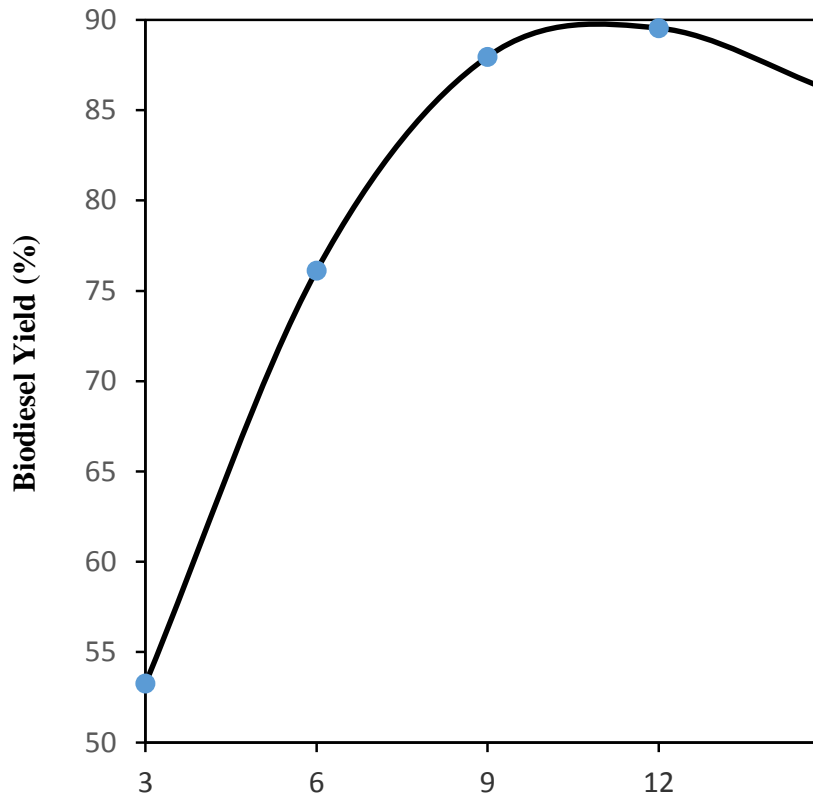

Fig. 2 Effect of methanol to oil ratio on the biodiesel yield.

The effect of the catalyst was evaluated at $9: 1,60^{\circ} \mathrm{C}$ and 60 minutes, constant methanol to ratio, temperature and time, respectively. The catalyst was varied from $0.3 \mathrm{wt} \%$ to $1.5 \mathrm{wt}$. $\%$. The effect of catalyst on the biodiesel yield is shown in fig. 3. There is an increase in biodiesel yield with an increase in catalyst concentration. Since the catalyst is there to speed up the reaction meaning it facilitates the forward reaction to reach equilibrium in a shorter space of time. The highest yield of
$87.41 \%$ was obtained at 0.9 wt. $\%$, but the catalyst load of from $0.9 w t \%$ to $1.5 \mathrm{wt}$. $\%$ lowered the percentage yield. The excess catalyst concentration increases the viscosity and also the formation of a gel and emulsion [15]. It was also observed that the sample became dark in colour when the catalyst concentration was increased. Another explanation to why there is a retardation in the yield as the catalyst concentration is increased is due to the fact that the $\mathrm{KOH}$ may react with the FFA present in the glyceride during the transesterification, resulting in the formation of soap by saponification, this may consume the catalyst and reduce the efficiency.

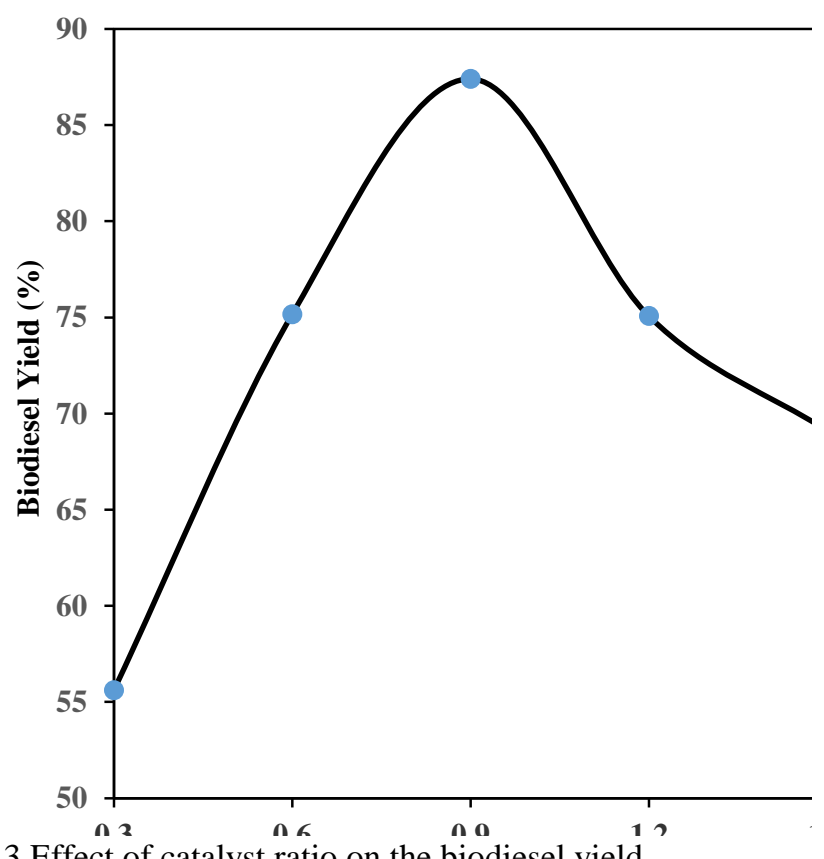

Fig. 3 Effect of catalyst ratio on the biodiesel yield

The effect of reaction temperature on the biodiesel yield was evaluated at 9:1, 0.9 wt. $\%$ and 60 minutes, constant methanol to ratio, catalyst ratio and time, respectively. The temperature was varied from $30^{\circ} \mathrm{C}$ to $70^{\circ} \mathrm{C}$ at $10^{\circ} \mathrm{C}$ increments. The effect of reaction temperature on the ester content is shown in fig. 4. There was an increase in the yield of the biodiesel from 30$60{ }^{\circ} \mathrm{C}$. The highest yield of $87.85 \%$ was obtained at $60{ }^{\circ} \mathrm{C}$. According to [16], the ideal reaction temperature is near the boiling point of the alcohol. Several studies reported getting a high biodiesel yield the best reaction temperature must be in a range of $50^{\circ} \mathrm{C}-70^{\circ} \mathrm{C}$ [14]. The yield did not much drop above boiling temperature; this was due to the reflux, condenser that was placed. The decrease can be due to the fact that the temperature is above the boiling point of methanol, and some of the methanol was in the vapour phase in the condenser, causing a reduction of methanol in the reaction media. The decrease of methanol concentration then shifts the reaction equilibrium to the left, which can decrease the yield. 


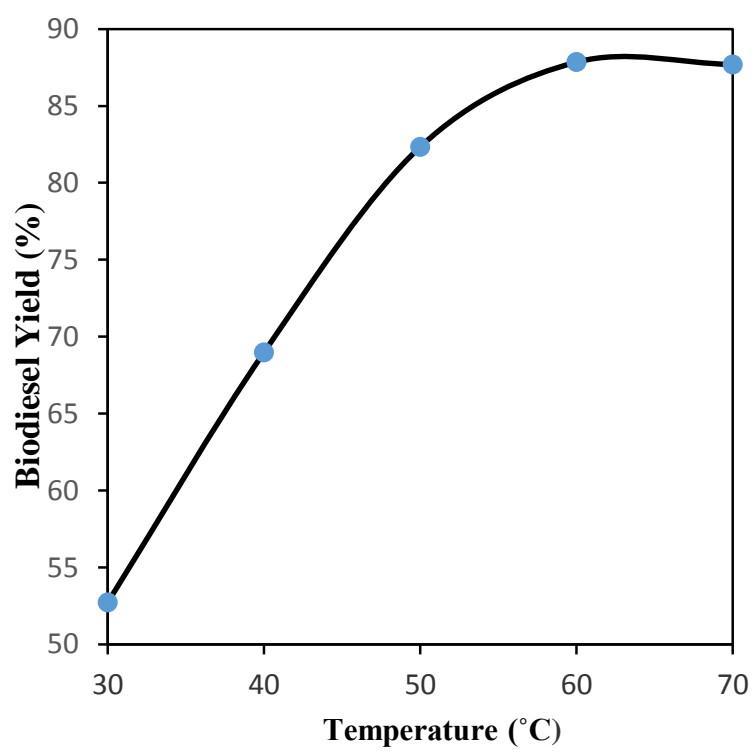

Fig. 4 Effect of temperature on biodiesel yield

The effect of reaction time on biodiesel yield was examined at $9: 1,0.9 \mathrm{wt} . \%$ and $60^{\circ} \mathrm{C}$, constant methanol to ratio, catalyst ratio and temperature, respectively. The effect of reaction time on the biodiesel yield was evaluated by varying time from 20 minutes to 80 minutes, as shown in fig. 5. As time was increased, an increase in the yield was also observed; this increase in yield is due to the fact that there was enough retention time for the reaction to occur. The maximum yield of $91.13 \%$ was obtained at 60 minutes. The yield remained relatively constant as the time was increased to 80minutes, a very slight decrease was observed; this is explained by the equilibrium reached. Further increase of time will cause a decrease in yield due reaction shifted to the left, causing loss of methyl esters and causing more fatty acids to form soaps [17].

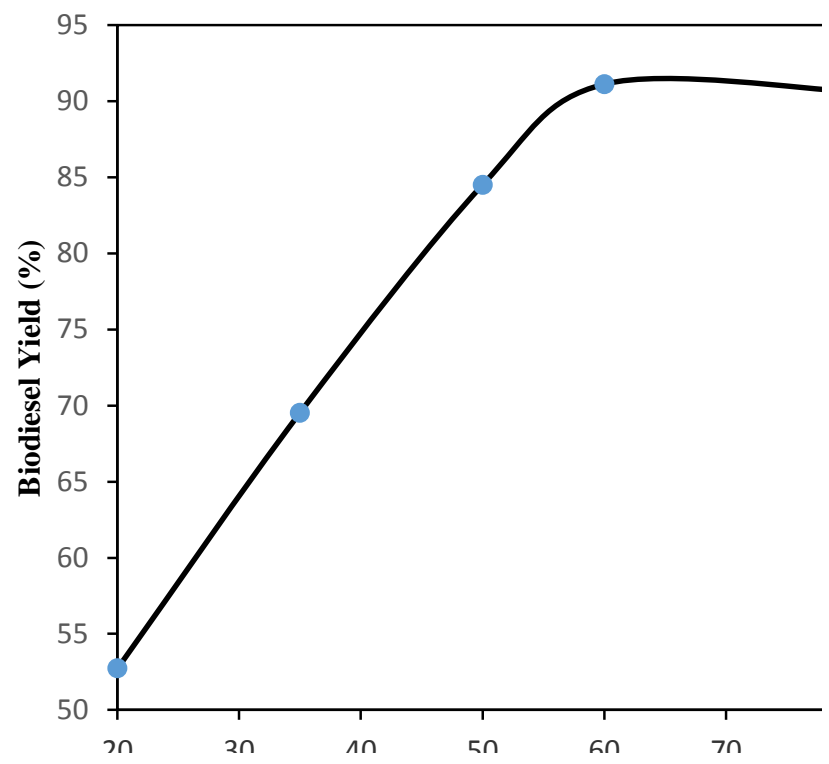

Fig. 5 Effect of temperature on the biodiesel yield

\section{B. Fuel properties}

The biodiesel sample produced at the optimum conditions was analysed to determine whether the biodiesel conforms to the ASTM standards. All the major fuel properties analysed were found to meet ASTM standards; these are summarised in table II.

TABLE II

FUEL PROPERTIES OF BIODIESEL FROM WASTE MARGARINE

\begin{tabular}{lcc}
\hline Properties & ASTM D6751-02 & Results \\
\hline Flash Point $\left({ }^{\circ} \mathrm{C}\right)$ & $>130$ & 148 \\
\hline Density $\left(\mathrm{g} / \mathrm{cm}^{-3}\right)$ & $0.86-0.9$ & 0.8687 \\
\hline $\begin{array}{l}\text { Water Content \% volume } \\
\text { fraction, } \max \end{array}$ & 0.05 & 0.0295 \\
\hline Viscosity $\left(\mathrm{mm}^{2} / \mathrm{s}\right)$ & 1.9 to 6.0 & 4.6503 \\
\hline Sulphur content $\mathrm{mg} / \mathrm{kg}, \max$ & 10 & 8.32 \\
\hline
\end{tabular}

\section{CONCLUSION}

The main objective of this project was to produce biodiesel from waste margarine, using waste margarine as a source of triglyceride, and the reaction was catalysed by Potassium hydroxide. The highest yield was obtained at $60{ }^{\circ} \mathrm{C}$, alcohol to oil molar ratio of $9: 1$, catalyst load of $0.9 \mathrm{wt} \%$, and 60 minutes reaction time. An increase in the amount of alcohol to oil increases biodiesel yield and biodiesel purity; this increases the miscibility and enhances the contact between the alcohol molecule and the triglycerides. An increase in reaction temperature beyond $60^{\circ} \mathrm{C}$ decreased the yield, so a maximum point was determined. The optimal time was achieved, and it meant there was enough retention time to occur. The biodiesel produced met the ASTM standards. Further works were recommended for the optimisation of biodiesel produced from margarine waste with different catalysts.

\section{ACKNOWLEDGEMENT}

The authors would like to acknowledge the technical assistance and support from the Department of Chemical Engineering at the Vaal University of Technology. And the Department of Energy: Fuel Testing and Analysis laboratory under the Ministry of Natural Resources and Energy Swaziland for their support and opening their laboratory for samples analysis.

\section{REFERENCES}

[1] R. W. Rice, A. K. Sanyal, A. C. Elrod, and R. M. Bata, "Exhaust emissions of butanol, ethanol and methanol-gasoline blends." Journal of Engineering for Gas Turbine and Power, vol. 113,199, pp.337-381. https://doi.org/10.1115/1.2906241

[2] Z. Utlu, and M. S. Kocak. "The effect of biodiesel fuel obtained from waste cooking oil on direct injection diesel engine performance." Renew Energy, vol. 35, 2008, pp.1936-1941. https://doi.org/10.1016/j.renene.2007.10.006

[3] M. Ewing, and S. Msangi, "Biofuels production in developing countries: Assessing tradeoffs in welfare foods." Environmental Science and Policy, vol. 12, 2009, pp.520-528. https://doi.org/10.1016/j.envsci.2008.10.002

[4] B. Gurunathan, and A. Ravi, "Biodiesel production from waste cooking oil using copper doped zinc oxide nanocomposite as heterogeneous catalyst.” Bioresource Technology, 188, 2015, pp.124-127. https://doi.org/10.1016/j.biortech.2015.01.012 
[5] C. I. L. Justino, R. Pereria, A. C. Freitas, T. A.P. Rocha-Santos, T. S.L. Panleleitchock, and A. C. Duarle. "Olive oil mill wastewaters before and after treatment: a critical review from the ecotoxicological point of view." Ecotoxicology, vol. 21, 2012, pp.615-629. https://doi.org/10.1007/s10646-011-0806-y

[6] C. C. Enweremadu and M. M. Mbarawa. "Technical Aspects of production and analysis of biodiesel from used cooking oils- A review." Renewable and sustainable energy reviews, vol. 13, 2009, pp.22052224. https://doi.org/10.1016/j.rser.2009.06.007

[7] G. Santori, G. D. Nicola, M. Mogile and F. Polonara. "A review analyzing the industrial biodiesel production practice starting from vegetable oil refining." Applied energy, vol. 92, 2012, pp.109-132.

[8] A. Z. Abdullah, N. Razali, H. Mootabadi, and B Salamatinia. "Critical technical areas for the future improvement in biodiesel technologies." Environmental Research Letter 2, 2007, pp.1-6.

[9] L. Arnaut, S. Famosinho, and H. Burrow. "Chemical Kinetics: from molecular structure to chemical reactivity," Amsterdam: Elsevier, 2007.

[10] M. Mittelbach, and B Trattnigg. "Kinetics of alkaline catalyzed methanolysis of sunflower oil." Fat Science, vol. 92, 1990, pp. 145-148.

[11] M. Agarwai, G. Chauhan, S. P. Chaurisa, and K. Singh, "Study of catalytic behaviour of $\mathrm{KOH}$ has homogeneous and heterogeneous catalyst for biodiesel production." Journal of Taiwan Institute of Chemical Engineers, vol. 43, 2012, pp.89-94. https://doi.org/10.1016/j.jtice.2011.06.003

[12] A. N. Phan, and T. M. Phan. "Biodiesel production from waste cooking oils." Fuels, vol. 87, 2008: pp.3490-3496. https://doi.org/10.1016/j.fuel.2008.07.008

[13] A. Banerjee and R. Chakraborty, "Parametric sensitivity in transesterification of waste cooking oil for biodiesel production- A review resources." Conservation and Recycling, vol. 53, 2008, pp.8691. https://doi.org/10.1016/j.resconrec.2009.04.003

[14] Meng, X., G. Chen, and Y. Wang, "Biodiesel production from waste cooking oil via alkali catalyst and its engine test." Fuel processing technology, vol. 89, 2008, pp. 851-857. https://doi.org/10.1016/j.fuproc.2008.02.006

[15] E. Modiba, P. Osifo and H. Rutto, "Biodiesel production from baobab (Adansonia digitata L.) seed kernel oil and its fuel properties", Industrial Crops \& Products. Elsevier B.V., vol. 59, 2014, pp. 50-54. 2014 https://doi.org/10.1016/j.indcrop.2014.04.044

[16] J. Cvengros, and Z. Cvengrosova. "Used frying oils and fats and their utilization in the production of methyl esters in high fatty acids." Biomass and Bioenergy, vol. 27, 2004, pp. 173-181

[17] D. Y. C. Leung, X. Wu and M. K. H. Leung, M, "A review on biodiesel production using catalyzed transesterification", Applied Energy. Elsevier Ltd, vol. 87, no. 44, 2014, pp. 1083-1095, 2010. https://doi.org/10.1016/j.apenergy.2009.10.006 